\title{
Educação em Saúde na escola: uma abordagem do currículo e da percepção de alunos de graduação em Pedagogia*
}

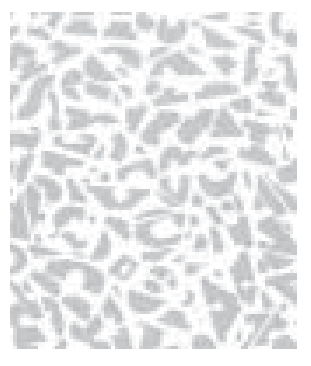

Valéria Marli Leonello ${ }^{1}$ Solange L'Abbate ${ }^{2}$

LEONELLO, V. M.; L'ABBATE, S. Health education in schools: an approach based on the curriculum and perception of undergraduate education students. Interface - Comunic., Saúde, Educ., v.10, n.19, p.149-66, jan/jun 2006.

Based on quantitative research, this article analyzes the way health education has been approached in the undergraduate education curriculum at a state university in Brazil. The investigation was divided into two stages: the first analyzes the curriculum of the course and the second investigates how education students see the topic, based on replies to a questionnaire. In regard to the curriculum, it was seen that two of the 73 disciplines analyzed deal explicitly with health education in schools. The replies showed that $65 \%$ of the students studied do not perceive this approach in their curriculums, even though $85 \%$ consider the work of teachers indispensable for the development of the theme in schools. The authors concluded that curriculums in the area of education should critically take the theme of health education into account, due to its importance for the life and citizenship of middle-school and high-school students.

KEY WORDS: health education. universities. higher education. curriculum.

Analisa-se, por meio de pesquisa descritiva, o modo como a Educação em Saúde tem sido abordada no currículo de graduação em Pedagogia de uma universidade estadual paulista. A investigação foi dividida em duas etapas: a primeira analisa o currículo do curso e a segunda, a compreensão dos estudantes de Pedagogia sobre o tema, por intermédio de respostas a um questionário. Em relação ao currículo, observou-se que duas, das 73 disciplinas analisadas trabalham, de modo explícito, a Educação em Saúde na escola. As respostas dos alunos revelaram que $65 \%$ dos respondentes não percebem esta abordagem no currículo, porém $85 \%$ consideram a atuação do pedagogo indispensável para o desenvolvimento do tema no ambiente escolar. Concluiu-se ser fundamental que o currículo do pedagogo contemple, criticamente, a temática da Educação em Saúde, dada sua relevância para a vida e a cidadania dos escolares de nível médio.

PALAVRAS-CHAVE: educação em saúde. universidades. ensino superior. currículo.

\footnotetext{
* Trabalho baseado em investigação de Iniciação Científica, realizado de janeiro de 2002 a janeiro de 2003 , com financiamento da Fundação de Amparo à Pesquisa de São Paulo - Fapesp.

${ }^{1}$ Programa de Pós-Graduação, Escola de Enfermagem, Universidade de São Paulo, SP. <valeria.leonello@gmail.com>

${ }^{2}$ Departamento de Medicina Preventiva e Social, Universidade Estadual de Campinas/Unicamp, SP. <slabbate@fcm.unicamp.br>
}

${ }^{1}$ Rua Ramiro de Santa Cruz Abreu, 116

Butantã - São Paulo, SP

Brasil - 05.592-120 


\section{Introdução}

Neste trabalho, abordamos a questão da Educação em Saúde inserida na escola, com base em uma pesquisa sobre a formação de pedagogos.

A escolha do tema reflete a mudança de paradigma em relação às práticas de saúde, antes fragmentadas e curativas e, atualmente, vistas numa concepção de assistência integral e inseridas no contexto da promoção à saúde, definida como: "o processo de capacitação da comunidade para atuar na melhoria da qualidade de vida e saúde, incluindo maior participação no controle desse processo" (Ministério da Educação apud Lervolino, 2000, p.8).

A promoção à saúde nos faz pensar na construção de práticas que colaborem para a construção e desenvolvimento de hábitos saudáveis, indivíduos responsáveis, autônomos e conhecedores do direito político, econômico e social à saúde (Ministério da Saúde apud Lervolino, 2000).

Para o desenvolvimento dessas práticas, há que se considerar a necessidade de definir campos de ação para a promoção da saúde. Dentre eles, estão: a construção de políticas públicas saudáveis; a criação de ambientes favoráveis; a reorientação dos serviços de saúde; o desenvolvimento de habilidades individuais; e o reforço da ação comunitária, por meio da responsabilidade social (Silveira, 2000).

Uma das estratégias que promovem a responsabilidade social é a Educação em Saúde, entendida, neste trabalho, como a combinação de atitudes e experiências de aprendizagem com objetivo de desenvolver o conhecimento dos indivíduos "sobre os determinantes da saúde, sobre o comportamento em saúde, e sobre as condições sociais que afetam seu próprio estado de saúde e o estado de saúde dos outro" (Silveira, 2000, p.34).

\section{Educação em Saúde no ambiente escolar}

Acreditamos que no ambiente escolar o indivíduo, em determinadas etapas da vida, apreende atitudes e habilidades que são articuladas às suas experiências vivenciadas no cotidiano. Essas conquistas orientam o aluno para o reconhecimento e expressão de suas necessidades, possibilitando a oportunidade de refletir sobre seu papel histórico e colaborando para possíveis transformações por intermédio da consciência e mudança social (Lervolino, 2000).

Neste sentido, a Educação em Saúde pretende "colaborar na formação de uma consciência crítica no escolar, resultando na aquisição de práticas que visem à promoção, manutenção e recuperação da própria saúde e da saúde da comunidade da qual faz parte" (Focesi, 1992, p.19).

\section{O educador}

Quando nos remetemos à escola como ambiente favorável para a Educação em Saúde, questionamos quais seriam os principais atuantes nesse processo? Inicialmente, em nossas discussões, consideramos a importância do profissional de saúde inserido na escola, tentando buscar caminhos que nos orientassem em relação a essa atuação.

Porém, ao investigar a questão, nos deparamos com a importância de quem trabalha diariamente e diretamente com os alunos, ou seja, o educador. Não desconsideramos a importância da atuação e integração da equipe de saúde na escola; ao contrário, a escola como equipamento social deve interagir e articular estratégias de promoção à saúde com essa equipe. 
Entretanto, elegemos como foco de atenção, neste trabalho, o profissional de educação que atua na escola. Não apenas o professor que está diretamente em contato com o aluno, como também aqueles que contribuem para o desenvolvimento do processo pedagógico, a exemplo do supervisor e do coordenador pedagógico. Representando de maneira abrangente esses profissionais, concluímos pela escolha do pedagogo.

Para isso, nos fundamentamos na discussão de alguns autores que consideram a importância da atuação consciente e crítica do educador, articulando teoria e prática vinculadas à realidade dos alunos. De acordo com Bagnato (1987), por exemplo, a Educação em Saúde no espaço escolar depende, em grande parte, do preparo acadêmico dos educadores. Alguns anos antes, Silva (1983) também já evidenciava a necessidade da formação crítica de educadores para que esses soubessem articular teoria e prática, vinculadas às condições de vida da população. O próprio Ministério da Saúde propõe a necessidade de formação e qualificação docentes para a abordagem da promoção à saúde em ambiente escolar (Ministério da Saúde, 2002).

\section{Objetivo da investigação}

O objetivo deste trabalho foi identificar o modo como a Educação em Saúde tem sido abordada no currículo de Graduação em Pedagogia, considerando a compreensão do tema pelos graduandos, tendo em vista sua atuação futura como educador e orientador.

\section{Metodologia}

O tipo de metodologia utilizada foi a da pesquisa descritiva, ou seja, "aquela em que se expõem características de determinada população ou fenômeno" (Tobar \& Yalour, 2001, p.69), sobretudo, quando se trata de situações pouco conhecidas, como é o caso deste trabalho.

A investigação foi dividida em duas etapas: na primeira, trabalhamos a abordagem do currículo do curso de Pedagogia da Universidade Estadual de Campinas, por meio de duas técnicas (a observação de ementas disciplinares e entrevista semi-estruturada com a coordenação de graduação do curso pesquisado). Na segunda etapa, procuramos identificar a compreensão do graduando de Pedagogia em relação à temática da Educação em Saúde, por intermédio de instrumento de pesquisa - questionário.

A consulta às ementas disciplinares foi feita mediante leitura exploratória do catálogo de graduação fornecido pela universidade. Buscamos por ementas disciplinares oferecidas ao curso pesquisado que trouxessem explicitamente os termos: "Educação em Saúde", "Saúde Escolar" e "Saúde". Entretanto, foram consideradas disciplinas que pudessem trazer alguma relação com a questão da saúde em ambiente escolar.

A entrevista semi-estruturada foi realizada com a coordenadora de graduação do curso de Pedagogia, em local e dia previamente acordados pelas pesquisadoras e pela coordenação do curso.

Na segunda etapa do trabalho, aplicamos um questionário, com perguntas abertas e fechadas, aos alunos do último semestre do curso.

Esse instrumento de pesquisa foi aplicado aos alunos dos períodos vespertino e noturno em horário de aula, em dia previamente combinado, e em comum acordo com a direção do curso de graduação em Pedagogia.

Foram prestados os esclarecimentos necessários aos estudantes para o 
preenchimento do questionário, e explicitado o respeito aos seus direitos de recusa na participação da pesquisa, bem como a liberdade e sigilo em relação às suas respostas, por meio do Consentimento Livre e Esclarecido, fundamentado na resolução 196/96 do Conselho Nacional de Saúde. Além disso, a pesquisa foi aprovada pelo Comitê de Ética e Pesquisa da Faculdade de Ciências Médicas da Unicamp, sendo realizada no período de janeiro de 2001 a janeiro de 2002.

\section{Resultados}

\section{Primeira etapa: observação do currículo}

\section{Para início de conversa: o que é um currículo?}

Na busca de referenciais teóricos para a definição de currículo, nos deparamos com uma infinidade de concepções, muitas vezes distintas entre si. No entanto, de acordo com Pedra (1997), essa diversidade não sugere a existência de diferentes realidades contextuais, mas sim interpretações distintas de vários autores.

Apesar das diferentes possibilidades de definições, observamos, de acordo com a literatura, que ao se considerar a estrutura curricular, deve-se refletir sobre o contexto social na qual essa estrutura está inserida. Tal visão crítica torna-se necessária para que se possa manter o objetivo da educação orientado para a transformação da realidade (Pedra, 1997; Torres, 1995; Saviani, $1994)$.

Visto desse modo, o currículo surge como processo norteador da forma de atuação da escola, de acordo com as mudanças e a reestruturação da sociedade na qual está inserido. Portanto, ao se pensar o currículo como um processo, construído conforme a realidade sociopolítica e econômica, defende-se a necessidade de sua constante reflexão e discussão, para entendê-lo como uma estrutura flexível e em permanente (re)construção (Jorge, 1996).

\section{Construindo um currículo}

De acordo com a coordenadora de graduação da Faculdade de Educação investigada, a estrutura curricular denomina-se pré-ativa ou prescritiva, isto é, um currículo construído a partir de dois enfoques: o normativo e o campo do saber específico da Pedagogia.

$O$ primeiro refere-se às normas e leis que regulamentam e norteiam a estruturação do currículo. No Brasil, compete ao Estado, por intermédio das Leis de Diretrizes e Bases (LDBs), controlar o sistema de ensino. Já o Conselho Nacional de Educação (CNE), órgão constituído por representantes da classe de pedagogos e assessores do Ministério da Educação, propõe as diretrizes curriculares para os cursos de nível superior do país. Portanto, a LDB e as diretrizes curriculares regulamentam e norteiam, respectivamente, o desenvolvimento do currículo do curso de graduação em Pedagogia.

\section{O currículo do curso de graduação em Pedagogia da Unicamp}

Ainda segundo a coordenação de graduação do curso, o princípio fundamental é a formação de pedagogos que entendam a educação como resultado da relação professor-aluno, ou seja, o processo de ensinoaprendizagem só ocorre com a constituição do sujeito educador que é, por excelência, o sujeito professor. 
Esse princípio perpassa toda a grade curricular estruturada para o curso (Quadro 1), organizada em oito semestres e constituída de disciplinas norteadas por um eixo teórico-metodológico que estimula o aluno a compreender a produção do conhecimento no campo da Pedagogia e ordena as disciplinas em obrigatórias, eletivas e estágios, totalizando 2.850 horas.

Quadro 1. Distribuição das disciplinas oferecidas durante o curso de Pedagogia por semestre - Campinas, 2002

\begin{tabular}{|c|c|c|c|c|c|c|}
\hline \multirow{2}{*}{$\frac{\text { Semestres }}{1^{\circ}}$} & \multicolumn{6}{|c|}{ Disciplinas oferecidas } \\
\hline & $\begin{array}{l}\text { EP107 Introdução à } \\
\text { Pedagogia - Org. } \\
\text { Trab.Ped. }\end{array}$ & $\begin{array}{l}\text { EP } 108 \\
\text { Pesquisa Pedagógica I }\end{array}$ & $\begin{array}{l}\text { EP } 140 \\
\text { Sociologia Geral }\end{array}$ & $\begin{array}{l}\text { EP } 122 \text { Introdução } \\
\text { à Psicologia }\end{array}$ & $\begin{array}{l}\text { EP } 130 \text { Filosofia } \\
\text { da Educação I }\end{array}$ & $\begin{array}{l}\text { EP } 109 \\
\text { Seminários de } \\
\text { Pesq. } \\
\text { Pedagógica I }\end{array}$ \\
\hline $2^{\circ}$ & $\begin{array}{l}\text { EP } 110 \text { História da } \\
\text { Educação I }\end{array}$ & $\begin{array}{l}\text { EP } 108 \\
\text { Pesquisa Pedagógica II }\end{array}$ & $\begin{array}{l}\text { EP } 340 \text { Sociologia } \\
\text { da Educação I }\end{array}$ & $\begin{array}{l}\text { EP } 123 \text { Psicologia } \\
\text { Educacional }\end{array}$ & $\begin{array}{l}\text { EP } 230 \text { Filosofia } \\
\text { da Educação II }\end{array}$ & $\begin{array}{l}\text { EP } 209 \\
\text { Seminários } \\
\text { dePesq. } \\
\text { Pedagógica II }\end{array}$ \\
\hline $3^{\circ}$ & $\begin{array}{l}\text { EP } 210 \text { História da } \\
\text { Educação II }\end{array}$ & $\begin{array}{l}\text { EP } 152 \text { Didática - } \\
\text { Teoria Pedagógica }\end{array}$ & $\begin{array}{l}\text { EP } 445 \text { Sociologia } \\
\text { da Educação II }\end{array}$ & $\begin{array}{l}\text { EP } 126 \text { Psicologia, } \\
\text { Educação e Pesquisa }\end{array}$ & $\begin{array}{l}\text { EP } 141 \\
\text { Comunicação } \\
\text { Educação e } \\
\text { Tecnologias }\end{array}$ & \\
\hline $4^{\circ}$ & $\begin{array}{l}\text { EP } 412 \text { História da } \\
\text { Educação III }\end{array}$ & $\begin{array}{l}\text { EP } 153 \text { Metodologia } \\
\text { do Ensino } \\
\text { Fundamental }\end{array}$ & $\begin{array}{l}\text { EP } 144 \text { Metodol. } \\
\text { da Pesquisa em } \\
\text { Ciências da } \\
\text { Educação I }\end{array}$ & $\begin{array}{l}\text { EP } 162 \text { Escola e } \\
\text { Currículo }\end{array}$ & $\begin{array}{l}\text { EP } 163 \text { Polít. } \\
\text { Educ.: Estr. e } \\
\text { Func. da Ed. } \\
\text { Básica }\end{array}$ & \\
\hline $5^{\circ}$ & $\begin{array}{l}\text { EP } 154 \text { Fundamentos } \\
\text { da Alfabetização }\end{array}$ & $\begin{array}{l}\text { EP } 159 \text { Prát. Ensino } \\
\text { nas Séries Inic. do } \\
\text { Ensino Fundamental }\end{array}$ & $\begin{array}{l}\text { EP } 145 \text { Metodol. } \\
\text { da Pesquisa em } \\
\text { Ciências da } \\
\text { Educação II }\end{array}$ & $\begin{array}{l}\text { EP } 155 \text { Fundamentos } \\
\text { do Ensino } \\
\text { de Matemática }\end{array}$ & $\begin{array}{l}\text { EP } 156 \text { Fundam. } \\
\text { do Ensino de } \\
\text { História e } \\
\text { Geografia }\end{array}$ & $\begin{array}{l}\text { EP } 157 \\
\text { Fundamentos } \\
\text { do Ensino de } \\
\text { Ciências }\end{array}$ \\
\hline $6^{\circ}$ & $\begin{array}{l}\text { EP } 111 \text { Fundamentos } \\
\text { da Educação } \\
\text { Especial }\end{array}$ & EP 200 Estágio I & $\begin{array}{l}\text { EP } 127 \\
\text { Pensamento, } \\
\text { Linguagem e } \\
\text { Desenvolvimento } \\
\text { Humano }\end{array}$ & $\begin{array}{l}\text { EP } 151 \text { Leitura e } \\
\text { Produção de Textos }\end{array}$ & $\begin{array}{l}\text { EP } 765 \\
\text { Fundamentos da } \\
\text { Educação Infantil }\end{array}$ & Eletiva \\
\hline $7^{\circ}$ & $\begin{array}{l}\text { EP } 142 \text { Educação e } \\
\text { Antropologia Cultural }\end{array}$ & EP 206 Estágio II & $\begin{array}{l}\text { EP } 808 \text { Trabalho } \\
\text { de Conclusão de } \\
\text { Curso I }\end{array}$ & $\begin{array}{l}\text { EP } 164 \text { Organização do } \\
\text { TrabalhoPedagógico e } \\
\text { Gestão Escolar }\end{array}$ & $\begin{array}{l}\text { EP } 463 \\
\text { Planejamento } \\
\text { Educacional }\end{array}$ & Eletiva \\
\hline
\end{tabular}

Fonte: In Form Ação da Faculdade de Educação, Unicamp, 2002

As disciplinas obrigatórias fornecem a essência do currículo, ou seja, são aquelas que os alunos devem freqüentar para que possam concluir o curso. Perfazem o total de 2.220 horas.

Já as eletivas compõem a estrutura diversificada do currículo, na qual o aluno tem autonomia para investir em suas áreas de preferências. No currículo geral, destina-se uma carga horária específica para a participação do aluno em disciplinas de sua escolha. Para concluir o curso, é necessário que o aluno cumpra 330 horas nessas disciplinas.

Além das disciplinas obrigatórias e eletivas, há os estágios supervisionados, que correspondem às atividades práticas realizadas em diversas instituições de ensino. 
Por último, há o núcleo temático, que se constitui numa proposta inovadora de articulação entre um conjunto de disciplinas que favorecem o aprofundamento de alguns campos de atuação. Por exemplo, existe um núcleo temático que trabalha educação e diversidade ética. Dessa forma, os alunos escolhem um núcleo, no total de oito existentes, e trabalham mais profundamente questões de seu interesse. O núcleo perfaz um total de 180 horas e é oferecido no final do curso, ou seja, no oitavo semestre.

\section{A inserção da Educação em Saúde no currículo: o que a estrutura normativa mostra?}

Apesar de não haver menção específica em relação à abordagem da saúde na escola, a nova Lei das Diretrizes e Bases (LDB), de 1996, consolida e amplia a participação do poder público no que se refere ao seu dever de assegurar a educação para todos, principalmente no ensino fundamental, colocando esse acesso como fator essencial para a formação de cidadãos (Demo, 1997).

Ao se propor a formar cidadãos conhecedores de seus direitos e deveres, o ensino na escola também se compromete a promover a Educação em Saúde, pois esta é essencial para a formação de indivíduos responsáveis e autônomos, conhecedores de seus direitos em relação à saúde.

No mesmo sentido, estão os Parâmetros Curriculares Nacionais (PCNs). Criados com base em discussões sobre os currículos oficiais, os PCNs surgem como proposta norteadora, tendo como objetivo "orientar e garantir a coerência das políticas de melhoria da qualidade de ensino, tornando-as acessíveis a todos, divulgando discussões, pesquisas e recomendações" (Lervolino, 2000, p.39).

Dentre as proposições dos PCNs, está a abordagem transversal de questões sociais, na qual temas de relevância social - como o ambiente, pluralidade cultural, orientação sexual, ética e saúde - seriam tratados em todas as disciplinas do currículo fundamental de maneira transversal, ou seja, perpassando todas as etapas das áreas curriculares O objetivo dessa nova abordagem é o de resgatar a dignidade humana, a igualdade de direitos, a participação ativa na sociedade e a co-responsabilidade pela vida social (Ministério da Educação e Cultura, 1998).

O contexto educacional oferecido pelas matérias transversais favorece a proposição de metas educativas, cujo eixo norteador do conjunto de aprendizagem a ser desenvolvido esteja em ressonância com as necessidades básicas e vitais da sociedade, entre elas, a saúde e qualidade de vida. (Busquetes \& Leal, 2000).

\section{Pesquisando o currículo de Pedagogia}

Tomando por base a observação do modo de construção do currículo, iniciamos a pesquisa das disciplinas que pudessem estar relacionadas ao nosso tema - a Educação em Saúde. Observamos ementas de disciplinas que abordassem, de maneira geral, a discussão e reflexão sobre Educação em Saúde, considerando seu contexto histórico e sua importância como estratégia para promoção à saúde no espaço escolar. Entretanto, não desconsideramos disciplinas que trouxessem aspectos relacionados à saúde, como, por exemplo: compreensão do corpo, sexualidade humana, entre outros.

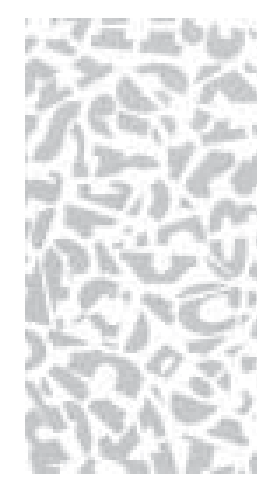




\section{Disciplinas obrigatórias}

As 39 disciplinas obrigatórias investigadas não trazem, explicitamente, os termos "Educação em Saúde", "Saúde Escolar" ou "Saúde". Entretanto, foram selecionadas duas disciplinas que parecem fazer uma aproximação entre as questões referentes à Educação e à Saúde (Quadro 2):

Quadro 2. Disciplinas obrigatórias relacionadas à prática de saúde - Campinas, 2002

\begin{tabular}{|c|c|}
\hline Disciplinas & Classificação da disciplina \\
\hline Fundamentos do Ensino de Ciências & Obrigatória \\
\hline Fundamentos em Educação Infantil & Obrigatória \\
\hline
\end{tabular}

A primeira disciplina, Fundamentos do Ensino de Ciências, trouxe a seguinte ementa:

Controvérsias metodológicas e condições extremas geradoras dos modelos clássicos da história do ensino de ciências. Concepções de Ciência, Ambiente, Educação e Sociedade subjacentes aos principais modelos de ensino de Ciências. Papel no ensino de Ciências no ensino de nível fundamental e inter-relações com os demais componentes disciplinares. (Universidade Estadual de Campinas, 2001, p.448)

De acordo com a ementa proposta, entendemos que a disciplina, apesar de não fazer menção à temática da Educação em Saúde em ambiente escolar, pode abordar aspectos relacionados, na medida em que se propõe a trabalhar com o contexto histórico do ensino de Ciências, disciplina essa que historicamente tem trazido a discussão das questões referentes à saúde. Entretanto, ressaltase que não fica explícito tal abordagem somente pela observação da ementa disciplinar.

A segunda disciplina, Fundamentos da Educação Infantil, traz em sua ementa a seguinte informação:

Análise dos fundamentos políticos, econômicos e sociais da educação infantil, ou seja, do atendimento de crianças de 0 a 6 anos.

Conceitos de infância, família e suas historicidades. Funções da educação infantil. Políticas de atendimento à infância. Creches e préescolas. Relações entre educação infantil e ensino fundamental. Articulações dos equipamentos de atendimento à criança de 0 a 6 anos com outras instituições. (Universidade Estadual de Campinas, 2002, p.455)

Observa-se que há uma preocupação da disciplina em trabalhar com as questões voltadas ao "atendimento à infância" e "a articulação dos equipamentos de atendimento". Entretanto, não há explicitamente a utilização do termo "Educação em Saúde" ou "Saúde Escolar" ou "Saúde".

\section{Disciplinas eletivas}

Nas 34 disciplinas eletivas também não foi encontrada ementa disciplinar que trouxesse os termos: "Educação em Saúde", "Saúde Escolar" ou "Saúde". 
Observam-se, porém, algumas ementas que parecem favorecer o desenvolvimento da temática (Quadro 3).

Quadro 3. Disciplinas eletivas relacionadas à prática de Saúde - Campinas, 2002

\begin{tabular}{|l|c|}
\hline Disciplinas & Classificação da disciplina \\
\hline Educação e Cidadania & Eletiva \\
\hline Escolas abertas à diversidade & Eletiva \\
\hline Educação e Sexualidade Humana & Eletiva \\
\hline Direito à Infância e Educação & Eletiva \\
\hline Oficina sobre direitos humanos e Cidadania & Eletiva \\
\hline Deficiência Mental e família & Eletiva \\
\hline Ética e Diversidade & Eletiva \\
\hline
\end{tabular}

As disciplinas selecionadas mencionam aspectos relacionados à saúde dos indivíduos, dentre eles: cidadania, direitos humanos, direito à infância, diversidades encontradas na escola, sexualidade humana e abordagem do aluno especial. Como tema transversal, certamente, as questões relativas à Educação em Saúde no ambiente escolar podem ser trabalhadas nas disciplinas escolhidas. Entretanto, essa proposição não é encontrada nas ementas disciplinares pesquisadas.

\section{Segunda etapa: abordagem dos alunos}

A segunda etapa da pesquisa foi realizada por meio de um questionário, com perguntas abertas e fechadas, aplicado aos alunos do último semestre do curso. O instrumento de pesquisa foi aplicado aos alunos dos períodos vespertino e noturno, em dia previamente combinado, e em comum acordo com a direção do curso de graduação em Pedagogia.

Como se pode observar na tabela abaixo (Tabela 1 ), o número total de respondentes foi de quarenta alunos, sendo 23 do período vespertino e 18 do noturno:

Tabela 1. Participação dos alunos na pesquisa de acordo com o período do curso - Campinas, 2002

\begin{tabular}{cccc}
\hline Período & Respondentes & Não Respondentes & Subtotal \\
\hline Vespertino $(\mathrm{V})$ & 22 & 01 & 23 \\
Noturno $(\mathrm{N})$ & 18 & 0 & 18 \\
\hline$(\mathrm{V})+(\mathrm{N})$ & $\mathbf{4 0}$ & $\mathbf{0 1}$ & $\mathbf{4 1}$
\end{tabular}

O número total de matriculados em cada período do curso era, à época do estudo, de 45 alunos. No entanto, devemos considerar que a aplicação do questionário foi feita em horário de aula, em uma determinada disciplina. Por abordarmos somente os alunos presentes nessa aula, não obtivemos o número total de matriculados.

A escolha de uma única disciplina e de uma mesma data para a aplicação do instrumento de pesquisa foi uma solicitação da própria coordenação do curso, para que os alunos interrompessem a aula em um único período e disciplina, não dificultando, assim, o cumprimento da programação normal do curso.

\section{A compreensão dos entrevistados sobre a Educação em Saúde}

No que se refere à primeira pergunta do instrumento, a questão, aberta, 
indagava aos respondentes sobre a compreensão deles em relação à Educação em Saúde. Tabulamos as respostas em algumas categorias, reconhecendo a impossibilidade de abarcar toda a riqueza e variedade dos conteúdos mencionados (Tabela 2). Por isso, as particularidades encontradas serão discutidas em cada categoria criada.

Tabela 2. Categorias de respostas referente à compreensão sobre Educação em Saúde. Campinas, 2002

\begin{tabular}{lcc}
\hline Respostas & Total & \% Total (40) \\
\hline Como orientações e discussões relacionadas à saúde em geral & 18 & 45,0 \\
Como aspecto importante a ser desenvolvido no ambiente escolar & 09 & 22,5 \\
Sem subsídios para responder a questão & 08 & 20,0 \\
Como uma disciplina específica & 02 & 5,0 \\
Como prática que estimule a ação social & 01 & 2,5 \\
Como elo entre práticas educativas e de saúde & 01 & 2,5 \\
Questão muito ampla & 01 & 2,5 \\
\hline Total & $\mathbf{4 0}$ & $\mathbf{1 0 0}$ \\
\hline
\end{tabular}

O primeiro aspecto que chama a atenção nessas respostas é referente à dificuldade em responder a questão, citada por $20 \%$ do total de alunos, devido à falta de subsídios teóricos relativos à temática. Um desses respondentes afirma nunca ter discutido a questão da Educação em Saúde no curso de Pedagogia. Outros dois alunos colocam que não há uma disciplina do curso que aborde esse tema.

Ao relacionarmos esses dados com a observação do currículo, entendemos que, para esses alunos, não há disciplinas que abordem explicitamente a questão da Educação em Saúde na escola. As disciplinas elencadas como possíveis responsáveis pelo tratamento dessa questão - Fundamentos do Ensino de Ciências e Fundamentos da Educação Infantil - não são citadas por eles.

Uma das respostas mais comuns à pergunta, foi a que relaciona Educação em Saúde na Escola com orientações e discussões sobre aspectos relacionados à saúde em geral. Dentro desta categoria, incluímos as citações referentes aos cuidados com o corpo, higiene, sexualidade, prevenção de doenças, alimentação e ambiente. É interessante ressaltar a ênfase dada à higiene e à prevenção de doenças. Das 18 respostas relacionadas, seis referiram a importância da orientação aos escolares sobre aspectos referentes à higiene, acrescentando fatores como alimentação adequada, sexualidade e ambiente.

Catalán (2001), ao defender a educação para o desenvolvimento social e político, lembra que, historicamente, as atividades educativas em saúde eram realizadas de maneira autoritária, impositiva e coercitiva e com caráter exclusivamente informativo, dando ênfase à prevenção das doenças. Para o autor, essa visão ainda está cristalizada na prática de alguns profissionais, dentre eles, os de educação.

Em relação à prevenção de doenças, cinco das 18 respostas consideravam este item como um dos aspectos a serem abordados na escola. Das cinco respostas, dois alunos resumem a Educação em Saúde na escola como forma de prevenir doenças. Esse entendimento vai ao encontro da concepção da saúde na qual, segundo Berlinguer (1989), os indivíduos só entendem o significado da saúde mediante a ausência de doença. Neste sentido, as práticas 
educativas em saúde tendem a reduzir-se a atividades preventivas, de cunho meramente informativo e coercitivo.

Para L'Abbate et al. (1992, p.82), essa abordagem deve ser transformada em uma concepção de Educação em Saúde como “campo privilegiado de relações interpessoais e sociais através das quais se realizam as práticas de saúde", favorecendo o desenvolvimento da adesão, compromisso e autonomia dos sujeitos coletivos envolvidos.

Deve-se ressaltar que tal concepção ainda não está difundida entre os estudantes pesquisados. Observamos que, dos quarenta respondentes, apenas um sujeito demonstrou entender a Educação em Saúde como vinculada às dimensões social e histórica.

\begin{abstract}
É uma questão que não pode ser dissociada da questão socialhistórica. Quem são os envolvidos? Quais as características da comunidade em que a escola está inserida? Que questões são relevantes e significativas para aquela população? Educação em Saúde deve participar de um projeto de ação social e mudança social.
\end{abstract}

Revela-se, no relato, a preocupação do graduando em relação ao contexto social, histórico e cultural dos sujeitos envolvidos nas atividades de Educação em Saúde e a importância desses sujeitos na transformação e mudança de suas condições de saúde.

O entendimento da educação como instrumento de luta social teve grande avanço com o educador brasileiro Paulo Freire, ao colocar como indispensável e inadiável "uma ampla conscientização das massas brasileiras, através de uma educação que as coloque numa postura de auto-reflexão e de reflexão sobre seu tempo e seu espaço". Para o autor, essa auto-reflexão fará desses sujeitos não mais expectadores, mas figurantes e autores da história (Freire, 1982, p.36).

Em relação às demais respostas a essa questão, encontramos nove alunos, ou seja, $22,5 \%$ do total, que, apesar de não especificarem suas concepções de Educação em Saúde no ambiente escolar, colocam a temática como sendo um aspecto importante a ser abordado na escola. Um respondente, inclusive, refere a necessidade de articulação entre atividades educativas e de saúde. Dois alunos, $5 \%$ do total, opinam sobre a necessidade de uma disciplina específica no conteúdo curricular para que a saúde seja abordada de maneira mais específica no ambiente escolar.

\title{
A possibilidade do atual currículo abordar a saúde na escola
}

A segunda questão pergunta aos respondentes sobre a possibilidade de o currículo de Pedagogia abordar a questão da saúde na escola. As respostas a esta questão estão demonstradas no Gráfico 1:

Gráfico 1. Referente à questão:"Você acha que o currículo de pedagogia aborda a questão da saúde na escola?"

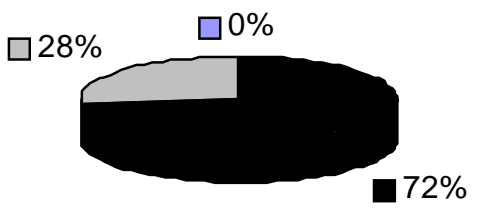

$$
\begin{aligned}
& \square \text { Sim } \\
& \square \text { Não } \\
& \square \text { Parcialmente }
\end{aligned}
$$

Intefare- Comunic, Saúde, Educ, v.10, n.19, p.149-66, jan/jun 2006 
A maioria dos entrevistados (72,5\%) considera que o currículo não possibilita abordagem da saúde na escola, enquanto a minoria $(27,5 \%)$ considera que o currículo aborda parcialmente a temática. Nenhum aluno considera que o currículo aborda a temática.

A explicação mais referida pelos que consideram que o currículo não aborda a temática foi a de que não há abordagem específica do tema em disciplinas obrigatórias e, por isso, o aluno não tem subsídios para trabalhar a temática.

Em contrapartida, alguns alunos sugerem que o tema não deva ser trabalhado na base teórica das disciplinas obrigatórias, pois esse é o núcleo estimulador de discussões filosóficas e epistemológicas, relacionadas especificamente ao campo da Pedagogia.

A maior parte dos que optaram pela alternativa que considera que o currículo aborda parcialmente a temática, relata que há uma abordagem, porém não relacionada diretamente à Educação em Saúde. Um aluno mencionou que não há abordagem dessa temática no currículo obrigatório, não explicitando essa questão. Outro aluno também relatou que há abordagem somente no último semestre, não explicitando a disciplina em que tal abordagem é colocada aos alunos.

\section{Conhecimento e lembrança de alguma prática de ensino que tenha abordado aspectos sobre Educação em Saúde no currículo atual}

A terceira questão indagava aos estudantes sobre o conhecimento em relação às práticas de ensino que tenham abordado aspectos referentes à Educação em Saúde. Os resultados estão sintetizados no Gráfico 2:

Gráfico 2. Referente a questão: "Ainda considerando o currículo atual, você tem conhecimento de alguma prática de ensino que tenha abordado aspectos referentes à Educação em Saúde?"

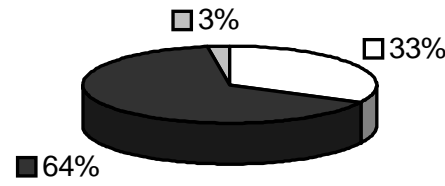

\begin{tabular}{|l|}
\hline Sim \\
$\square$ Não \\
$\square$ Não Respondeu
\end{tabular}

A maioria dos respondentes (65\%) não tem conhecimento ou não se lembra de nenhuma prática de ensino que tivesse abordado a temática durante o curso de Pedagogia. Uma parcela pequena (3\%) não respondeu a essa questão; e, para os que relataram alguma experiência na graduação sobre atividades educativas em saúde (32,5\%), foi solicitado que descrevessem em qual(is) disciplinas havia ocorrido esse contato. As mencionadas encontram-se na Tabela 3: 
LEONELLO, V. M.; L'ABBATE, S.

Tabela 3. Disciplinas elencadas pelos alunos - Campinas, 2002

\section{Disciplinas}

Fundamentos de Educação Especial

Educação, Corpo e Arte

Fundamentos do Ensino de Ciências

Educação e Sexualidade Humana

Pensamento, linguagem e desenvolvimento

Fundamentos em Educação Infantil

Temas Transversais em Saúde

Total de citações

\section{Classificação da disciplina Subtotal de citações}

\begin{tabular}{cc} 
Obrigatória & 6 \\
Obrigatória & 4 \\
Obrigatória & 3 \\
Eletiva & 2 \\
Obrigatória & 1 \\
Obrigatória & 1 \\
Eletiva & 1 \\
\hline
\end{tabular}

Observa-se que todas as disciplinas selecionadas pelos alunos também são relatadas na etapa de abordagem do currículo, mediante consulta das ementas disciplinares (Quadro 4). Excetuam-se as disciplinas: "Educação, Corpo e Arte"; "Pensamento, linguagem e desenvolvimento", e "Temas Transversais em Saúde" que, apesar de ter sido referida por um aluno, não constava do currículo, pois não estava incluída nas disciplinas eletivas oferecidas pelo Catálogo de Graduação de 2001, conforme análise anterior.

Quadro 4. Disciplinas elencadas durante a fase de abordagem do currículo - Campinas, 2002

\begin{tabular}{|l|c|}
\hline Disciplinas & Classificação da disciplina \\
\hline Fundamentos do Ensino de Ciências & Obrigatória \\
\hline Fundamentos em Educação Infantil & Obrigatória \\
\hline Educação e Cidadania & Eletiva \\
\hline Escolas abertas à diversidade & Eletiva \\
\hline Educação e Sexualidade Humana & Eletiva \\
\hline Direito à Infância e Educação & Eletiva \\
\hline Oficina sobre direitos humanos e Cidadania & Eletiva \\
\hline Deficiência Mental & Eletiva \\
\hline
\end{tabular}

É interessante notar que as duas disciplinas obrigatórias mais citadas pelos alunos não correspondem às duas disciplinas relacionadas durante a observação do currículo. Isto evidencia que, para esses alunos, as disciplinas "Fundamentos da Educação Especial" e “Educação, Corpo e Arte" tiveram maior relação com o entendimento que eles fazem de Educação em Saúde.

\footnotetext{
A atuação efetiva do pedagogo referente à Educação em Saúde na escola

Essa questão solicitava, ao alunos, que fizessem uma classificação da atuação do pedagogo em relação à Educação em Saúde na escola. Essa classificação poderia ser: indispensável e importante; dispensável, mas importante; e dispensável e sem importância (Tabela 4). Foi solicitado aos respondentes que justificassem suas respostas.
} 
Tabela 4. Classifcação da efetiva atuação do pedagogo referente à educação em saúde na escola - Campinas, 2002

\begin{tabular}{lcccc}
\hline Respostas & Vespertino & Noturno & Subtotal & \% Total (40) \\
\hline Indispensável e importante & 17 & 17 & 34 & 85,0 \\
Dispensável, mas importante & 01 & 01 & 02 & 5,0 \\
Dispensável e sem importância & 01 & 0 & 01 & 5,0 \\
Outro & 03 & 0 & 03 & 5,0 \\
\hline Total & $\mathbf{2 2}$ & $\mathbf{1 8}$ & $\mathbf{4 0}$ & $\mathbf{1 0 0}$
\end{tabular}

Observa-se que $85 \%$ do total de participantes da pesquisa consideram a atuação do pedagogo como indispensável e importante, o que nos mostra a sensibilização e a responsabilização dos graduandos do curso investigado em relação ao desenvolvimento da Educação em Saúde na escola. As justificativas para essa opinião foram diversas, conforme mostra a Tabela 5:

Tabela 5. Justificativa dos alunos que consideram a atuação do pedagogo frente à saúde escolar como indispensável e importante - Campinas, 2002

\begin{tabular}{lccc}
\hline Categorias & Vespertino & Noturno & Subtotal \\
\hline $\begin{array}{l}\text { O espaço escolar deve formar o aluno integralmente, } \\
\text { incluindo a abordagem sobre a saúde }\end{array}$ & 03 & 04 & 07 \\
$\begin{array}{l}\text { O espaço escolar é um ambiente importante para essa } \\
\text { abordagem }\end{array}$ & 03 & 00 & 03 \\
A atuação do pedagogo é importante para prevenção e & 03 & 05 & 08 \\
orientação sobre problemas relacionados à saúde & & & \\
Porque saúde é fundamental para vida & 01 & 00 & 01 \\
Porque faz parte da formação da criança & 02 & 03 & 05 \\
Porque a saúde influencia o aprendizado & 00 & 01 & 01 \\
Para melhorar a qualidade de vida dos alunos & 03 & 00 & 03 \\
Para modificar hábitos relacionados à saúde & 00 & 01 & 01 \\
Porque é um tema transversal & 00 & 01 & 01 \\
Outros ${ }^{*}$ & 02 & 02 & 04 \\
\hline Total & $\mathbf{1 7}$ & $\mathbf{1 7}$ & $\mathbf{3 4}$ \\
\hline
\end{tabular}

*Esses respondentes relatam a importância da atuação sem justificar suas respostas.

Observamos que há certa predominância em dois aspectos: o relacionado à formação integral do graduando (sete das 34 respostas) e o que se refere à Educação em Saúde como forma de prevenção e orientação sobre problemas relacionados à saúde (oito respostas).

Três alunos reforçam a importância do espaço da escola para abordagem de aspectos relacionados à saúde. Além disso, demonstram a preocupação de que, em algumas situações, a escola é o único local onde o aluno pode tomar contato com a temática da saúde, por isso, a importância da atuação do educador. Esta posição é apoiada por Martinez (1996), quando sugere as diferentes contribuições do ambiente escolar para saúde. Entre elas, o autor cita a participação desse espaço na formação cultural do aluno; a conformação de um ambiente que fornece/forneça a base da preparação para o mundo do trabalho; e, finalmente, os conhecimentos específicos de cada disciplina em relação à saúde.

Quanto aos que relataram que a atuação do pedagogo é dispensável, mas 
importante, obtiveram-se as seguintes respostas: “Não é prioridade da escola, no entanto, os alunos (alguns) recebem esse tipo de orientação só na escola". "Normalmente, a Educação em Saúde fica a cargo dos professores, principalmente de Ciências. O pedagogo deveria cuidar de montar um projeto mais amplo".

Ressalta-se que, ao pensarmos a Educação em Saúde, não estamos colocando em segundo plano a tarefa específica do espaço escolar, já que isso seria totalmente incoerente com a proposta de se tratar a saúde como tema transversal. Pensada como um aspecto que permeia o conjunto das experiências vivenciadas pelo escolar, a Educação em Saúde deve ser construída em colaboração com todas as disciplinas e, portanto, permear toda a proposta curricular (Ministério da Saúde \& Ministério da Educação e Cultura, 2002).

Considerando o total de respostas obtidas nessa questão, concluímos que os futuros pedagogos, em sua maioria, mostram-se sensibilizados e responsáveis pela questão da Saúde na escola, independente do modo como encaram e percebem essa temática.

Relacionando essas últimas informações com a questão referente à formação acadêmica do pedagogo para a abordagem da Educação em Saúde, observamos que, apesar dos alunos de Pedagogia sentirem-se sujeitos importantes e indispensáveis na promoção à saúde do escolar, prevalece o entendimento de que tal abordagem não está presente ou não é explicitamente colocada no conteúdo curricular durante sua formação acadêmica.

\section{Opiniões sobre a necessidade de promover mudanças de atitudes e comportamentos no escolar em relação à saúde.}

Nesta quinta e última questão, perguntamos a opinião dos alunos referente ao que é necessário para promover mudanças de atitudes e comportamentos no escolar em relação à saúde. Para facilitar a observação dos resultados obtidos, distribuímos o conjunto de respostas em categorias: A, B, C e D (Tabela 6).

Tabela 6. Opiniões sobre a necessidade de promover mudanças de atitudes e comportamentos no escolar em relação à saúde -Campinas, 2002

\begin{tabular}{lcccc}
\hline Categorias & Vespertino & Noturno & $\begin{array}{c}\text { Subtotal de } \\
\text { citações }\end{array}$ & \% Total (40) \\
\hline $\begin{array}{l}\text { A- Relacionado com o método pedagógico e } \\
\text { de comunicação para abordar a temática } \\
\text { com o aluno }\end{array}$ & 08 & 06 & 14 & 35 \\
$\begin{array}{l}\text { B- Relacionado com a preparação de } \\
\text { professores e do currículo de Pedagogia }\end{array}$ & 04 & 04 & 08 & 20 \\
$\begin{array}{l}\text { C- Relacionado com a abordagem da } \\
\text { temática nos conteúdos curriculares do }\end{array}$ & 03 & 03 & & \\
$\begin{array}{l}\text { escolar } \\
\text { D- Relacionado com trabalho em conjunto }\end{array}$ & 02 & 01 & 06 & 15 \\
$\begin{array}{l}\text { com comunidade, escola e saúde } \\
\text { E- Relaciona A, B e D }\end{array}$ & & & & \\
F- Relaciona A e C & 01 & 00 & 01 & 7,5 \\
G- - Outros & 00 & 01 & 01 & 2,5 \\
H- Não Respondeu & 02 & 03 & 05 & 2,5 \\
\hline Total & 02 & 00 & 02 & 12,5 \\
\hline
\end{tabular}


A categoria A abrange o conjunto de respostas que referem a mudança de comportamento e de atitudes do escolar em relação à saúde e à necessidade de utilização de diferentes métodos pedagógicos e/ ou de comunicação, como, por exemplo: discussões, orientações, palestras, aulas e campanhas.

Em seguida, na categoria $B$, relacionada à preparação dos professores e do currículo do curso, que forma esses profissionais para uma possível mudança de atitudes e comportamentos do escolar em relação à saúde, estão $20 \%$ das respostas. Alguns argumentos são citados abaixo:

É necessário que o currículo do curso de Pedagogia trabalhe esse assunto e que alunos desse curso adotem uma nova postura em relação à saúde e as informações sobre ela, não deixando as informações apenas para os médicos e enfermeiros.

É necessário que os profissionais da escola tenham subsídios suficientes para saber lidar com a saúde da escola em si e, para isto, é necessário, por parte das faculdades de educação, estar abrindo espaço para disciplinas da área de saúde no curso de Pedagogia.

Observamos, no primeiro depoimento, a preocupação do aluno em relação à mudança de atitude dos próprios profissionais em relação ao que eles entendem por Educação em Saúde na Escola, sugerindo que, desde a formação acadêmica, a discussão seja apresentada ao pedagogo.

Já o segundo argumento, além de referir a importância da formação do educador para a abordagem da temática na escola, considera que, no currículo de Pedagogia, deve haver um espaço formal, por meio de disciplinas específicas, para discussão de temas relacionados à saúde.

A categoria C, com $15 \%$ das respostas, inclui as respostas que consideram o modo como a abordagem da saúde é tratada no currículo, como responsável por essa provável mudança de comportamento.

Nessa categoria, foram inseridas respostas que consideram a necessidade de uma abordagem específica, por intermédio de uma disciplina (dois alunos); opiniões favoráveis à abordagem transversal da saúde (um aluno); relatos sobre a importância da temática fazer parte do conteúdo curricular da escola (três alunos); e, finalmente, uma sugestão de aulas "mais interessantes", para que favoreçam a mudança de comportamentos e de atitudes dos alunos em relação à saúde.

A categoria D, que representa apenas $7,5 \%$ das respostas, considera que mudanças de atitudes e de comportamentos relacionados à saúde só são possíveis se houver uma construção crítica e coletiva com todos os agentes envolvidos, isto é, professores, alunos, pais, comunidade, profissionais de saúde. Ressalta, ainda, que, sem essa discussão coletiva, não é possível envolver nem a escola, nem a comunidade:

Para mudanças de comportamentos e atitudes são necessários conhecimentos e condições materiais para que as mudanças aconteçam, caso se façam necessárias. E mesmo assim, nem sempre o que é passado pela escola será tido como certo e único modelo a seguir, pois o sujeito está inserido em outros grupos os quais lhe dão outras referências. E há termos que envolvem outros aspectos que podem, mesmo com o conhecimento teórico influenciar e muito em suas atitudes. 
Aqui encontramos a crítica ao modelo informativo e com caráter coercitivo. De acordo com Ramos (1989), tais práticas baseiam-se na educação como forma de adaptação à ordem social, fazendo com que os indivíduos mudem de comportamento e atitudes em relação à sua saúde de acordo com o modelo médico vigente.

Essa forma de conceber a Educação em Saúde não estimula a autonomia do indivíduo, pelo contrário, suprime-a de tal forma que o indivíduo não é sujeito do processo educativo, mas objeto passivo e aquém da construção reflexiva sobre suas condições de vida e de saúde (Cardoso de Melo, 1981; Apesar de encontrarmos uma crítica em relação a esse modelo hegemônico na saúde, apenas um aluno ( $2,5 \%$ do total de respondentes), levantou a discussão sobre a temática. Grande parte dos estudantes de Pedagogia investigados (35\% do total) ainda não consegue fazer a correlação entre atividades educativas em saúde e processo de construção de autonomia.

\section{Conclusões}

Ao abordarmos o currículo do curso investigado utilizando a técnica de leitura exploratória das ementas disciplinares, observamos que não há disciplinas que tragam explicitamente a temática da Educação em Saúde na escola.

Entretanto, consideramos a possibilidade do currículo em questão trabalhar com a temática da Educação em Saúde de maneira transversal, ou seja, perpassando as disciplinas obrigatórias e optativas do curso. Dessa forma, não haveria a necessidade de trazer a questão explícita na ementa disciplinar.

Entretanto, ao questionarmos os alunos, observamos que a maioria (65\%) ainda não identifica a Educação em Saúde no currículo, fato que nos faz questionar a existência da abordagem transversal do tema durante o curso. Acresce-se a isso que a maior parte dos alunos (85\%) considera a atuação do pedagogo importante e até indispensável para o desenvolvimento da Educação em Saúde no ambiente escolar.

Apesar da importância dada à temática, notamos também que o entendimento da Educação em Saúde, para esses alunos, volta-se, principalmente, para uma abordagem reducionista da saúde, na qual o processo de mobilização social e construção da autonomia dos escolares e da comunidade é considerado, apenas, por um número reduzido de graduandos.

Ao estudarmos a inserção desta temática no currículo desse curso, entendemos que o principal eixo norteador da educação escolar e, portanto, atributo do papel do educador, é a construção e desenvolvimento da cidadania e autonomia dos escolares. Nesse contexto de princípios democráticos, nos quais se incluem a dignidade da pessoa humana, igualdade de direitos, participação e co-responsabilidade pela vida social, "a educação cida dã concorre para a compreensão da saúde como direito. Mais do que isso, promove o exercício desse direito através da capacitação para agir, individual e coletivamente" (Ministério da Saúde \& Ministério da Educação, 2002, p.8).

Dessa forma, consideramos necessário e fundamental que o currículo da formação do pedagogo possibilite a reflexão crítica do aluno referente a tal temática, com o objetivo de que o entendimento desse aluno no campo da Educação em Saúde ultrapasse uma concepção fragmentada, medicalizada e reducionista. Afinal, acreditamos na importância de o currículo ser flexível e adaptado à realidade social, expressando assim "uma visão de mundo, de 
homem, de sociedade e, portanto, de educação e, também, de saúde" (Bagnato, 1994, p.148).

Nossas conclusões permitem considerar que o primeiro, senão o maior, desafio para a melhoria das condições de vida da população e, conseqüentemente, da promoção da saúde, passa por um maior comprometimento das instâncias governamentais, pelo processo de planejamento e efetivação de políticas públicas saudáveis. Entretanto, é igualmente instigante a tentativa de, mediante uma mobilização coletiva consciente e crítica, envolver o conjunto de atores sociais incluídos nesse processo - profissionais de saúde, de educação e a própria comunidade.

Concluímos, finalmente, pela necessidade urgente de uma maior articulação entre os responsáveis pelos setores da educação, da saúde e representantes da comunidade, no sentido de refletir e debater as temáticas da Educação e da Saúde e, sobretudo, a relação entre os dois campos. Acreditamos que tal articulação irá contribuir para a construção de uma concepção mais integrada e crítica da Educação em Saúde e também da Saúde em Educação, capaz de nortear ações coletivas e planejadas de saúde e de educação que sejam condizentes com a realidade social.

\section{Referências}

BAGNATO, M. H. S. Licenciatura em enfermagem: para quê?. 1994. Tese (Doutorado) - Faculdade de Educação, Universidade Estadual de Campinas, Campinas.

BERLINGUER, G. A doença. São Paulo: Hucitec, 1988.

BRASIL. Ministério da Educação e Cultura. Parâmetros curriculares nacionais: terceiro e quarto ciclos do ensino fundamental: introdução aos parâmetros curriculares nacionais. Brasília, 1998.

BRASIL. Ministério da Saúde. A promoção da saúde no contexto escolar [online]. Rev. Saúde Pública, n.4, v.36, p.533-5, 2002. Disponível em: <http://www.scielo.br/scielo.php?script=sci_arttext\&pid=S0034$89102002000400022 \&$ Ing=pt\&nrm=iso\&tlng=pt>. Acesso em: 10 mai. 2002.

BRASIL. Ministérios da Saúde e da Educação. Secretaria de Políticas de Saúde 0 projeto saúde na escola: texto de apoio. Brasília: Ministério da Educação e Cultura, 2002.

BUSQUETS, M. D.; LEAL, A. A. Educação para saúde. In: BUSQUETS, M.D.; CAIZOS, M.; FERNÁNDEZ, T.; LEAL, A.; MORENO, M.; SASTRE, G. Temas transversais em Educação: bases para uma formação integral. 6.ed. São Paulo: Ática, 2000. p.61-103.

CATALAN, V. C. La transversalidad y la escuela promotora de salud. Rev. Esp. Salud Publica. [on-line]. n.6, v.75, p.505-16, 2001. Disponível em: <http://wwwscielo.isciii.es/ scielo.php?script=sci_arttext\&pid=S1135-57272001000600003\&lng=es\&nrm=iso\&tlng=es $>$. Acesso em: 12 nov. 2001.

DEMO, P. A nova LDB: ranços e avanços. São Paulo: Papirus, 1997.

FOCESI, E. Uma nova visão de Saúde Escolar em Saúde na escola. Rev. Bras. Saúde Escolar, n.2, p.19-21, 1992.

FREIRE, P. Educação como prática da liberdade. Rio de Janeiro: Paz e Terra, 1982.

JORGE, L. Inovação curricular: além da mudança dos conteúdos. Piracicaba: UNIMEP, 1996.

L'ABBATE, S.; SMEKE, E. L. M.; OSHIRO, J. H. A Educação em Saúde como um exercício de cidadania. Saúde em Debate, n.37, p.81-5, 1992. 
LEONELLO, V. M.; L'ABBATE, S.

LERVOLINO, S. A. Escola promotora da saúde: um projeto de qualidade de vida. 2000.

Dissertação (Mestrado) - Faculdade de Saúde Pública, Universidade de São Paulo, São Paulo.

MARTINEZ, A. M. La escuela: un espacio de promoción de salud. Psicol. Esc. Educ., v.1, n.1, p.1924, 1996.

MELO, J. A. C. Educação sanitária: uma visão crítica. São Paulo: Cortez , 1981. (Cadernos Cedes, 4).

OSHIRO, J. H. Educação para a saúde nas instituições de Saúde Pública. 1988. Dissertação

(Mestrado) - Filosofia da Educação, Pontifícia Universidade Católica, São Paulo.

PEDRA, J. A. Currículo, conhecimento e suas representações. 4.ed. Campinas: Papirus, 1997.

RAMOS, C. L.; MELO, J. A. C. ; SOARES, J. C. R. S. Quem educa quem? Repensando a relação médico-paciente. In: COSTA, N. R.; MINAYO, C. S.; RAMOS, C. L.; STOTZ, E. N. (Orgs.) Demandas populares, políticas públicas e saúde. Petrópolis: Vozes, 1989. p.145-63. (Coleção Saúde e Realidade Brasileira, 2).

SAVIANI, N. Saber escolar: currículo e didática: problemas da unidade conteúdo/método no processo pedagógico. Campinas: Autores Associados, 1994.

SILVA, J. I. A educação do educador. A formação do educador em debate. Cad. Cedes, v.1, n.2, p.39-42, 1983.

SILVEIRA, G. T. Escola promotora da saúde: quem sabe faz a hora! 2000. Tese (Doutorado) Faculdade de Saúde Pública, Universidade de São Paulo, São Paulo.

TOBAR, F.; YALOUR, M. R. Como fazer teses em Saúde Pública. Rio de Janeiro: Fiocruz, 2001. TORRES, J. O curriculum oculto. Portugal: Porto Editora, 1995.

UNIVERSIDADE ESTADUAL DE CAMPINAS. Catálogo dos cursos de graduação. Campinas, 2001. p.90-4.

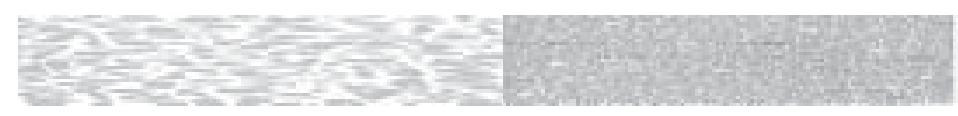

LEONELLO, V. M.; L'ABBATE, S. Educación en la salud en la escuela: un abordaje del currículo y de la percepción de alumnos de graduación en Pedagogía. Interface Comunic., Saúde, Educ., v.10, n.19, p.149-66, jan/jun 2006.

Mediante la investigación descriptiva, este artículo analiza la manera cómo la educación de salud ha sido abordada en el currículo de graduación en pedagogía de una universidad provincial paulista. La investigación fue dividida en dos etapas: la primera analiza el currículo del curso y la segunda, la comprensión que los estudiantes de pedagogía tienen del tema, por intermedio de respuestas a un cuestionario. Con relación al currículo, se observó que dos de las 73 disciplinas analizadas trabajan explícitamente la Educación en Salud en la escuela. Las respuestas de los alumnos demostraron que $65 \%$ de los encuestados no perciben ese abordaje en su currículo, aunque $85 \%$ consideran la actuación del pedagogo indispensable para el desarrollo del tema en el ambiente escolar. Se concluye que es fundamental que el currículo del pedagogo contemple, críticamente, la temática de la Educación en Salud, debido a su importancia para la vida y la ciudadanía de los estudiantes secundarios.

PALABRAS CLAVE: educación de salud. universidades. educación superior. curriculum. 